\title{
A optimización da coordinación de prácticas externas a través dunha APP
}

\author{
Piñeiro-Otero, Teresa \\ Facultade de Ciencias da Comunicación, Universidade da Coruña.
}

\section{RESUMO}

A evolución do ensino superior cara a unha apendizaxe baseada en competencias implicou unha importante transformación dos contidos, enfoques, e interaccións educativas. 0 peso dos criterios de empregabilidade na definición destas competencias tense proxectado nunha maior atención ás prácticas externas nas titulacións.

A diversidade de perfís profesionais e a cohabitación de prácticas curriculares e extracurriculares dota de grande complexidade á coordinación de prácticas. Coordinadores e titores teñen que dedicar unha parte importante do seu tempo á organización e xestión de todo o proceso en detrimento dun apoio e seguemento de calidade de estudantes e titores da empresa durante a estadía de prácticas.

Nesta liña o obxecto deste texto é o de efectuar unha aproximación ás potencialiades do emprego dunha aplicación de xestión de proxectos na Coordinación de Prácticas. A partir da experiencia do Grao de Comunicación Audiovisual da Universidade da Coruña, afóndase nas melloras do uso desta APP Asana- para todo o proceso.

PALABRAS CLAVE: Prácticas externas, APP, Xestión de proxectos, Comunicación Audiovisual, Coordinación de prácticas 


\section{CITA RECOMENDADA:}

Piñeiro-Otero, T. (2019): A optimización da coordinación de prácticas externas a través dunha APP. En De la Torre Fernández, E. (ed.) (2019). Contextos universitarios transformadores: construíndo espazos de aprendizaxe. III Xornadas de Innovación Docente. Cufie. Universidade da Coruña. A Coruña (pág. 83-96).

DOI capítulo: https://doi.org/10.17979/spudc.9788497497121.083

DOI libro: https://doi.org/10.17979/spudc.9788497497121

\section{ABSTRACT}

The evolution of higher education towards competency-based learning involved a major transformation of educational contents, approaches, and interactions. The weighting of employability criteria in the definition of these competences was projected in a greater attention to external practices in degrees.

The diversity of professional profiles and the cohabitation of curricular and extracurricular practices gives great complexity to the coordination of practices. Coordinators and tutors have to dedicate an important part of their time to the organization and management of the whole process to the detriment of a support and follow-up of quality of students and tutors of the company during the internship stay.

In this line the object of this text is to make an approximation to the potentialities of the use of a project management application in the Coordination of Practices. Based on the experience of the Degree in Audiovisual Communication of the University of A Coruña, the improvements in the use of this APP Asana- for the whole process are deepened.

KEY WORDS: Internships, APP, Project management, Audiovisual Communication, Training in-company support. 


\section{INTRODUCIÓN}

No momento actual as prácticas externas constitúen unha realidade inherente á formación dos estudantes universitarios. Xa como parte dos plans de estudios dos grados, xa como extracurriculares, o certo é que as prácticas preprofesionais trascenden a propia denominación para derivar nunha experiencia integrada tanto coas restantes materias do temario como con outras actividades formativas que desenvolve 0 estudantado ao longo da súa vida académica. Universidade e empresa, deste xeito, deben fornecer os estudantes de aprendizaxes de influencia mutua. Unha concepción que está detrás da aprendizaxe experiencial de Kolb (1984) así como doutros modelos pedagóxicos baseados na acción [prácticas] e reflexión arredor desta.

A integración do Practicum nos plans de estudos das titulacións en comunicación xurdidas ao abeiro do Espazo Europeo de Educación Superior (EEES), supuxo unha redefinición das prácticas preprofesionais. Se ben as prácticas das antigas licenciaturas de Ciencias da Comunicación nunca tiveron a entidade dos Practicum de Ciencias da Saúde ou Ciencias da Educación, as estadías en empresas detentaron un rol crucial na formación e indución empregando o termo proposto por Collison, Kozina,Lin, Ling, Matheson, Newcombe Zogla (2009)- dos futuros profesionais do Xornalismo, Comunicación Audiovisual ou Publicidade e Relacións Públicas.

A propia esencia das Ciencias da Comunicación, cuxas especialidades supoñen profesións constituídas como ciencias, reforza 0 valor destes períodos de prácticas preprofesionais en entidades. Seguindo a Follari (2010), estes títulos xorden de profesións que teñen esixido a formación universitaria para a habilitación da súa forza laboral. Así, a aparición das primeiras facultades de Ciencias da Información en España (década dos 70) e a formación impartida nestas, teñen o seu orixe nas antigas Escolas Oficiais de Xornalismo, Cinematografía e Publicidade, encargadas da formación destes profesionais no contexto español.

A proximidade entre os títulos universitarios de Ciencias en Comunicación e 0 ámbito profesional faise especialmente patente nos graos xurdidos tras a aprobación do Real Decreto 
1393/2007, do 29 de outubro, polo que se establece a ordenación das ensinanzas universitarias oficiais, como se pode observar nos novos graos de Comunicación Dixital, Comunicación Corporativa, Comunicación Internacional etc.

Por outro lado, a eclosión das titulacións de comunicación nos anos 90 propiciou o salto á docencia universitaria de numerosos profesionais da comunicación. A integración á docencia de profesionais en activo, contribuiu á reputación das prácticas externas así como a percepción da súa necesidade para ingresar nun sector cada vez máis competitivo, cada vez mái saturado.Asimesmo, como sinala Lamuedra (2007), a asunción de responsabilidades, a carga de traballo e /ou horarios de profesionais supón unha motivación para os estudantes e un elemento propulsor da experiencia.

Os períodos de prácticas, con independencia da súa esencia, permiten ao estudantado entrar en contacto coa profesión (ou profesións) de afondar nunha determinada especialización ou de descartala por completo.

Así, ao marxe dos seus planos de estudos, as Facultades de Ciencias da Información, primeiro, e as Facultades de Ciencias da Comunicación, despois, comezaron a ofertar prazas de prácticas en entidades como complemento da súa formación. Estas prácticas extracurriculares, que cohabitan na formación dos futuros egresados en Comunicación cos Practicum, soen desenvolverse fóra do calendario académico e incluso en épocas vacacionais, cuestión que refrenda su carácter eminentemente instrumental e a súa aparente desvinculación dos currícula universitarios.

Non entanto, como sinala Follari (2004), a formación dos futuros profesionais da comunicacióin esixe a abordaxe de aspectos conceptuais que trascendan as demandas do mercado laboral nun momento concreto, de modo que poida garantirse a súa adaptación á práctica profesional en cada momento así como a capacidade crítica arredor desta.

Deste xeito, a universidade prepara 0 estudante para 0 choque coa realidade do medio, aínda que autores como Ezcurra, Grecca e Saegh (2012) critican que non se discuta 0 suficiente sobre as diferenzas de criterios que marcan a actividade nun espazo e outro. 


\subsection{AS PRÁCTICAS NO GRAO EN COMUNICACIÓN AUDIOVISUAL DA UNIVERSIDADE DA CORUÑA}

Como subliñan Gordillo e Checa (2015) 0 artellamento das prácticas externas nos graos de Comunicación ten sido diversa.

Malia que existe un certo consenso na temporizacioón das prácticas curriculares no derradeiro curso da titulación, a súa carga lectiva varía dende os 6 aos 24 créditos ECTS. Do mesmo xeito sucede co encaixe entre prácticas curriculares e extracurriculares: mentres que nalgunhas titulacións existe unha interacción natural, noutras a incoporación do Practicum conlevou a completa substitución das prácticas extracurriculares.

No grao de Comunicación da Universidade da Coruña existe unha cohabitación máis ou menos harmónica das prácticas curriculares e extracurriculares. Unha situación que pode relacionarse co caracter optativo do Practicum, a súa limitada carga lectiva (6 ECTS) e a multiplicidade de perfís profesionais para os que habilita o Grao.

A titulación en Comunicación Audiovisual na Universidade da Coruña está especializada en animación, interacción e multimedia dende unha perspectiva analítica, creativa e técnica. Unha orientación única no sistema universitario español no momento de implantación da Licenciatura (curso 2003-2004) e que, posteriormente, se mantería no Grao.

Na adaptación da titulación ao Espazo Europeo de Educación Superior (EEES) seguiuse o Libro Blanco de los estudios de Comunicación (ANECA 2005) que prevé o 40\% de contidos propios de cada universidade; neste caso un módulo específico de deseño e animación que dota os egresados de grande potencial para o seu ingreso no actual mercado laboral.

Ademais dos roles profesionais tradicionais, no ámbito dos medios de comunicación ou na produción cinematográfica e televisiva, a efervescencia do sector dos contidos online e das industrias creativas dixitais teñen propiciado unha multiplicación de perfiles laborais -dende 0 community manager até os produtores transmedia (véxase o informe de PWC e Fundación Atresmedia (2017)- para os que os estudantes de comunicación da UDC están especialmente preparados. 
Esta multiplicidade de perfís tense reflectido nunha maior complexidade na escolla de especialización, o que leva a moitas persoas a desenvolver diversas estadías de prácticas, en ocasións en ámbitos profesionais diversos, de cara a acotar e/ou afianzar os seus intereses profesionais.

Ao mesmo tempo, na procura dunha formacióin instrumental axeitada, que os faga diferenciarse nun contorno laboral cada vez máis saturado (o Grao de Comunicación Audiovisual está presente nas tres universidades galegas, e forma parte da oferta académica da maior parte das universidades españolas), moitos estudantes combinan estadías de prácticas curriculares e extracurriculares na mesma entidade.

Malia que non todos os estudantes optan por desenvolver unha estadía en empresas, a coordinación centralizada de todas as prácticas externas sumada ás posibilidades de combinación de diversas estadías de prácticas, coas súas particularidades, multiplica a complexidade da súa xestión.

\subsection{A XESTIÓN DE PRÁCTICAS COMO UN MEDIO}

Con independencia da súa articulación nos plans de estudos universitarios, 0 desenvolvemento dun sistema de prácticas de calidade no marco dunha titulación esixe un importante traballo de xestión. Un traballo que na universidade non adoita estar profesionalizado, senón que disputa o tempo da persoa coordinadora de prácticas co labor docente e de invetigación. As esixencias docentes do día a día máis o valor que detentan os outputs investigadores no desenvolvemento da traxectoria académica, condena á xestión de prácticas a detentar o último lugar nas obrigas do PDI.

Asemade, nas interaccións con coordinadores e cordinadoras de prácticas doutras titulacións da Universidade da Coruña, así como coas persoas xestoras de prácticas en títulos de Comunicación noutras universidades do sistema español, ponse de manifesto unha maior atención á busca de entidades e a burocracia que acompaña o proceso desde a súa adhesión como entidades colaboradoras á incorporación-avaliación de estudantes en prácticas, en 
detrimento do tempo de orientación e seguimento do alumnado e a relación coas empresas. Unha circunstancia que afecta negativamente á calidade das prácticas en tanto a relación co estudante e co titor profesional limítase a contactos puntuais, en moitos casos apremiados pola necesidade de cubrir informes de seguimento e avaliación.

Malia que a compartimentación das labores de xestión de prácticas é complexa de solucionar sen máis recursos humanos, así como tamén é difícil que ocupen un lugar prioritario nas tarefas das persoas responsables da coordinación e/ou titorización das prácticas académicas, si se poden implementar fórmulas que limiten a carga de xestión e liberen tempo para a interacción (de calidade) con todos os axentes implicados.

Neste senso, o obxecto do presente texto é 0 de afondar nas potencialidades de empregar unha aplicación de xestión de proxectos para a coordinación e titorización das prácticas académicas, a partir da experiencia desenvolvida do Grao de Comunicación Audiovisual da Universidade da Coruña.

\section{DESCRICIÓN DA EXPERIENCIA}

Dende 0 curso 2009-2010, no que asumín a coordinación das prácticas externas no Grao de Comunicación Audiovisual, comecei a proba de fórmulas para simplificar a xestión e seguimento das prácticas académicas.

Coa implantación do Grao en Comunicación Audiovisual e, máis concretamente, coa oferta de prácticas curriculares esta xestión fíxose máis complexa o que acuciou a busca de métodos e/ou ferramentas que permitisen compaxinar o rol docente, investigador e xestor con certa calidade.

Despois de empregar fórmulas mixtas, de combinar as bases de datos convencionais con sistemas de calendarios e alarmas online como Google Calendar, sen que supuxesen unha mellora cualitativa na xestión de prácticas, optouse por probrar unha aplicación específica para a xestión de proxectos. 
Nese momento o papel da Coordinación de prácticas no Grao de Comunicación Audiovisiual complicárase, dado o imporante volume de estudantes en prácticas curriculares e extracurriculares, as diferenzas na xestión de cada tipo mais as posibles combinacións de estadías e as súas posibilidades de recoñecemento dentro da marxe das 750 horas fixado polo Regulamento de Prácticas Académicas Externas do Estudantado da Universidade da Coruña (Aprobado en Consello de Goberno de data 23 de abril de 2013 e modificado 027 de febreiro de 2015).

No curso 2016-2017, de forma paralela áos procesos de xestión tradicionais das prácticas, comezouse a experimentar con Asana, unha aplicación web para a xestión de proxectos que conta con versión de escritorio e de smartphone. Esta aplicación segue un modelo Premium, mais o plan gratuíto permite traballar con un volume de tarefas adecuado ás necesidades da Coordinación de Prácticas.

Se ben as funcionalidades de Asana son similares ás doutras APP de xestión de proxectos, a súa selección estivo marcada polo emprego previo da aplicación noutros ámbitos. A adecuación desta ferramenta confirmouse recentemente cando Asana integrou unha opción de sincronización cos calendarios online más habituais como Google Calendar, Apple Calendar ou Outlook.

Estas potencialidades, sumada a súa adecuación para a xestión de prácticas, levaron ao seu uso como ferramenta clave para coordinar-titorizar as estadías en empresas do estudantado do Grao en Comunicación Audiovisual. 0 emprego desta ferramenta supuxo un salto cualitativo no día a día. Mais que un simple volcado da documentación e tarefas ao ámbito online, a integración desta aplicación permitiu unha mellora de todos o procesos, o que se reflectiu nunha xestión optimizada das prácticas.

\subsection{CÓMO SE ARTELLOU ESTA XESTIÓN?}

Para poder adaptar calquera aplicación de xestión de proxectos á coordinación de prácticas cómpre considerar e tratar a cada estudante como se fose unha tarefa independiente. Este 
tratamento permite organizar -e tratar- cada un dos pasos implícitos no desenvolvemento de prácticas externas como subtarefas.

Así, no espazo dedicado a cada estudante [tarefa] intégranse pasos como sinatura do convenio pola entidade, sinatura de convenio pola UDC, plan formativo, comezo da estadía, metade da estadía, fin da estadía/avaliación titor e memoria final do estudante.
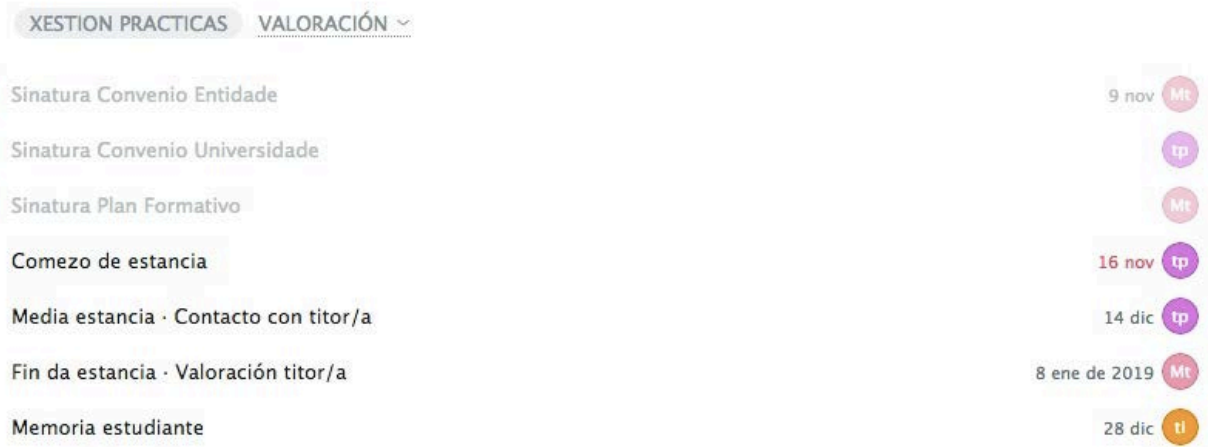

Imaxe 1. Espazo de estudante na aplicación coas subtarefas diversos estados de xestión. Na columna da dereita sinálanse a data de finalización e os responsables da mesma

As pincipais fases -Documentación, Estadía, Valoración, Memoria- darán lugar ás diferentes columnas nas que se estrutura o espazo de traballo da aplicación.



Imaxe 2. Organización de estudantes na APP segundo a fase de xestión na que se sitúan. 
Estas subtarefas son iguais para todos estudantes, o que varía son os prazos e as persoas implicadas en cada unha destas fases.

Cada subtarefa permite fixar unha data límíte, subir a documentación correspondente e dar acceso ás persoas implicadas nas diferentes etapas do proceso a través da súa conta de email. Estas subtarefas constitúen apartados estancos respecto aos restantes pasos na xestióndesenvolvemento-avaliación da estadía de prácticas de cada estudante e ao marxe do restante alumnado.

Unha vez completadas as subtarefas, coa correspondente data de entrega e as persoas participantes -que poden ser estudante en prácticas, titor/a da entidade e titor/a académico- a aplicación convírtese nunha push tecnologie en tanto é a ferramenta a que avisa (vía e-mail ou notificación no móvil) da proximidade dun prazo, do cumprimento do prazo e incluso do seu retraso ata que a coordinación de prácticas non sinale como rematada a subtarefa concreta.

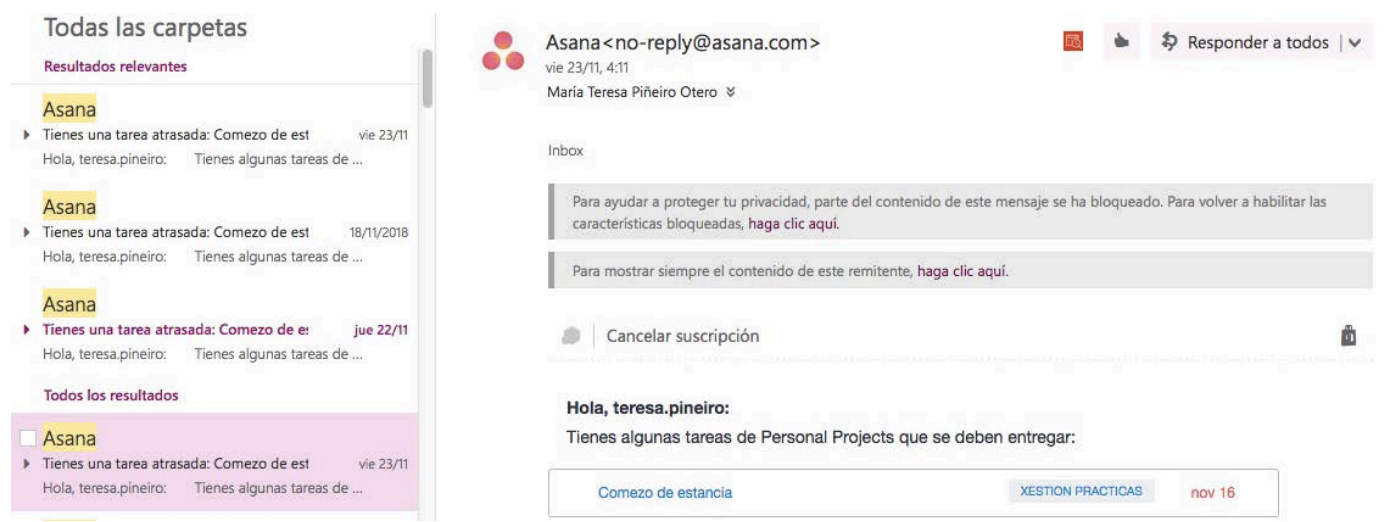

Imaxe 3. Notificacións automáticas de prazos no e-mail.

Dende unha perspectiva máis tradicional, 0 acceso a APP (nas súas diferentes versións) efectúase a través dunha primeira pantalla onde se sinalan os procesos con datas próximas de finalización. Asemade, a organización do espazo de traballo en columnas identificadas con cada unha das fases permite organizar os estudantes, arrastrándoos dun estado a outro, de 
modo que nun golpe de vista se poida ter unha perspectiva xeral da situación na que se atopan todos os procesos de prácticas.

\section{RESULTADOS}

A integración desta aplicación, nas súas versións web e móvil, no día a día da coordinación de prácticas conlevou diversas melloras tanto nos procedementos das prácticas curriculares e extracurriculares, como no seguimento e titorización dos estudantes.

Así, téñense identificado as seguintes melloras do uso desta aplicación de xestión de proxectos para a coordinación de prácticas:

- Acceso en calquera momento e lugar. Tanto a versión para smartphone desta aplicación como a web facilitan a coordinación de prácticas e 0 acceso a toda a documentación e contactos precisos en cada unha das fases, sempre que se dispoña de acceso á Internet. Esta posibilidade permite a xestión e seguemento das prácticas fóra da Facultade e do horario de traballo, e incluso aproveitar tempos outrora perdidos como os momentos de espera ou de desprazamento. Esta posibilidade de acceso ubicuo non esixe o seu emprego, senón que brinda oportunidades para compaxinar a coordinación de prácticas con outras tarefas docentes-investigadoras, como estadías ou congresos, e facilita a xestión de conflitos naquelas estadías que se desenvolven en períodos non lectivos.

- Automatización do proceso de solicitude/remisión de documentación. 0 emprego desta aplicación para a coordinación de prácticas esixe unha maior dedicación inicial, para a programación das subtarefas, mais permite automatizar todo o proceso de remisión de documentación, enviando no prazo fixado os impresos anexos a todos os participantes. Así, por exemplo, na data final da estadía os titores profesionais reciben de forma automática o impreso de avaliación dos estudantes, liberando tempo e simplificando tarefas á Coordinación de Prácticas. 
Na mesma liña, a concreción de datas de entrega nas subtarefas, automatiza a remisión de recordatorios ás persoas responsables tanto antes da data como, de forma periódica, unha vez pasada esta. Seguindo o exemplo anterior, ao crear unha subtarefa para a avaliación do/a estudante a persoa titora recibirá un correo electrónico solicitando a entrega do formulario ata que a Coordinación de Prácticas sinale a súa recepción.

Esta automatización do proceso tamén permite crear recordatorios específicos para a xestión de prácticas, por exemplo cando se cumpre a metade da estadía de prácticas na entidade de cara a facilitar o seguemento do estudante e a relación cos titores profesionais.

- Mimiza 0 tempo de xestión. A maior parte do tempo de coordinación de prácticas dedícase á burocracia de modo que a automatización de procesos, como a remisión de documentación ou o recordatorio da súa cumprimentación, limita o tempo destinado á xestión de prácticas.

- Mellora seguimento e a relación con estudantes e titores. A automatización dos procesos de xestión libera tempo para a interacción con estudantes e titores, o que permite obter información cualitativa, habitualmente oculta nos informes e memorias, para a mellora de todo o proceso. 0 incremento dos contactos e 0 tempo dedicado a cada un vai repercutir positivamente na organización das prácticas na selección de entidades e estudantes e, por ende, na calidade do sistema de prácticas.

- Facilita o traballo de varios titores. A automatización de procesos e a creación dun calendario compartido con alertas para cada unha das tarefas e subtarefas repercute nunha organización máis eficiente de diferentes titores, así como no cumprimento de prazos e entregas.

En definitiva, a introdución desta aplicación para a coordinación de prácticas limita o tempo dedicado a xestión, mellora a interacción entre todos os axentes implicados e facilita 0 
seguemento de todo o proceso habilitando tempo e novas oportunidades para a relación cos estudantes e titores académicos.

\section{CONCLUSIÓNS}

A integración dunha aplicación de xestión de proxectos para a coordinación de prácticas ten suposto un cambio substancial na organización e segumento das estadías en entidades dos estudantes.

Se ben non supuxo unha transformación real do proceso, o emprego desta APP incrementou a eficiencia da xestión de prácticas, liberando tempo para a interacción co estudante e 0 responsable da empresa. Esta interacción permite coñecer o desenvolvemento das prácticas e as percepcións e valoracións dos axentes implicados en diversos momentos da estadía, e así obter información de valor permita corrixir posibles desviacións e implenentar melloras que repercutan positivamente na calidade dos sistema de prácticas.

Entre as limitacións da integración desta APP para a coordinación de prácticas debe sinalarse a necesidade de consentimento de estudante e titor da entidade para 0 ingreso do seu e-mail dentro da plataforma. A automatización de procesos conleva un importante volume de e-mails que poden resultar molestos.

Non entanto, no caso de que titor da entidade ou estudante non autoricen o uso do seu e-mail, a aplicación pode empregarse para a automatización de recordatorios de fin de prazo para a coordinación de prácticas.

En calquera caso, o emprego desta aplicación para a Coordinación de Prácticas permite unha maior compatibilidade entre as tres esferas nas que se sustenta a actividade académica: docencia, investigación e xestión.

\section{REFERENCIAS}

ANECA (2005). Libro blanco de títulos de Grado en Comunicación. Madrid. 
Ezcurra, D., Greca, L. \& Saegh, D. (2012). Educación Superior: Tensiones y debates en torno a una transformación necesaria. Villa María: Eduvim.

Collinson, V., Kozina, E., Lin, Yk., Ling, L., Matheson, I., Newcombe, L. \& Zogla, I. (2009). Professional development for teachers: A world of change. European Journal of Teacher Education, 32(1), pp. 3-19. Doi: 10.1080/02619760802553022

Follari, R. (2004). Modificaciones epistemológicas actuales, oferta educativa y organización curricular. Mendoza: Facultad de Ciencias Políticas y Sociales de la UNCuyo.

Follari, R.A. (2010). El curriculum y la doble lógica de inserción: lo universitario y las prácticas profesionales. Revista iberoamericana de educación superior, 1(2), pp. 20-32. Recuperado de https://bit.ly/2zVUCHw

Gordillo, M.M. \& Checa, A. (2015). Prácticas curriculares. En J.L. Gómez Mompart \& M. Herrero Subías (Coords.). Jornadas de Formación y Empleo en Comunicación. ATIC. Recuperado de https://bit.ly/2zVKcaR

Kolb, D. (1984). Experiential Learning. New Jersey: Prentice Hall Inc.

Lamuedra, M. (2007). Estudiantes de Periodismo y prácticas profesionales: el reto del aprendizaje. Comunicar, 28: 203-2011. https://bit.ly/2Pi5ncu

PWC \& Fundación Atresmedia (2017). Informe Empleos del futuro en el sector audiovisual. Recuperado de https://bit.ly/2QAhFx3 